\title{
EL HUMOR GRÁFICO, UNA HERRAMIENTA POTENTE PARA ENSEÑAR Y APRENDER
}

\section{THE CARTOON AS A POWERFUL TEACHING- LEARNING TOOL}

\section{Lucía Bugallo*, Constanza Zinkgräf**, Ana Pedrazzini*}

*Instituto Patagónico de Estudios de Humanidades y Ciencias Sociales (IPEHCS-CONICET) UNCo - ** Universidad Nacional del Comahue luciabugallo@gmail.com

\section{Palabras Clave Resumen}

humor gráfico El objetivo de este trabajo es poner de relieve la potencialidad educativa de la producción de humor gráfico en niños y adolescentes desde un dibujo enfoque integral y multimodal de la alfabetización. Esto supone superar una lógica instrumental según la cual su inclusión en la currícula escolar escritura alfabetización multimodalidad se realiza de forma ilustrativa con el fin de abordar otros contenidos curriculares. Un mayor aprovechamiento de este género implica dimensionar su riqueza discursiva, complejizando una visión que lo sitúa como un objeto meramente de entretenimiento. Durante 2015 y 2016 se dictaron en San Carlos de Bariloche (Río Negro, Argentina) seis talleres de producción e interpretación de humor gráfico en contextos educativos formales e informales, a partir de los cuales se obtuvieron 121 viñetas humorísticas producidas por niños y adolescentes de 9 a 18 años. En este trabajo se presenta un panorama de este corpus. Se describen los temas abordados y se analizan diversos recursos verbales, visuales y multimodales puestos en juego para entretener, divertir, expresar una visión personal y/o hacer reflexionar. Los resultados evidencian que los participantes se implicaron con entusiasmo en la producción de las viñetas y abordaron temas significativos, se plantearon complejos desafíos cognitivos y semióticos y lograron producciones originales y/o sofisticadas. 


\section{Keywords Abstract}

cartoon The aim of this paper is to highlight the educational potential of the production (creation) of cartoons in children and adolescents from an drawing integral and multimodal approach to literacy. This implies overcoming the instrumental logic by which their inclusion in the school curricula writing is merely illustrative with the purpose of addressing other curricular contents. A better use of this genre would imply emphasizing its

literacy discursive richness, surpassing the perspective that considers it solely multimodality as an object of entertainment. Between 2015 and 2016 six workshops on cartoon production and interpretation were conducted in San Carlos de Bariloche (Río Negro, Argentina) both in formal and informal educational contexts, resulting in 121 cartoons, created by children and adolescents between 9 and 18 years old. In this paper we present a view of this corpus. The issues addressed are described while we analyze the variety of verbal, visual and multimodal resources put into play to entertain, enjoy, reflect upon and /or express a personal perspective. The results demonstrate that participants got involved in the production of cartoons with enthusiasm and focused on meaningful issues, raising complex cognitive and semiotic challenges while managing to build original and/or sophisticated productions.

\section{ALFABETIZACIÓN MULTIMODAL}

Desde un enfoque integral y multimodal, concebimos la alfabetización como un proceso que comprende las prácticas de aprendizaje, enseñanza y uso de diversos modos o sistemas semióticos, como la escritura; el dibujo; el habla; la notación numérica, musical, química; la gestualidad; entre otros. La multimodalidad se basa en la suposición de que la representación y la comunicación implican una multiplicidad de modos, los cuales tienen el potencial de contribuir de forma significativa en la producción de sentido (Jewitt, 2009; Kress, 2010). Esto implica abandonar el logocentrismo que durante mucho tiempo predominó en la cultura occidental, en tanto el lenguaje verbal es uno entre muchos otros modos que intervienen en las interacciones humanas. Los sentidos construidos en un modo siempre están entretejidos con los sentidos producidos por otros modos que co-participan o cooperan en un mismo evento comunicativo. De hecho, la interacción entre los modos es, en sí misma, una parte de la producción del sentido.

El enfoque multimodal empezó a cobrar mayor protagonismo en ámbitos académicos y educativos hacia fines del siglo pasado (New London Group, 1996), atendiendo a la explosión multimedial en donde la variedad, cantidad y multidireccionalidad de la información circundante no sólo conforma la cultura de los aprendices, sino también influye en sus modos de comunicación. Pese a este protagonismo, si atendemos al caso de la articulación de los modos verbal y visual en el contexto educativo, Cruder (2008) advierte sobre la escasa atención que se dedica a dicha articulación en libros de texto, planes curriculares y contenidos básicos de la formación docente en la Argentina. Destaca que el valor epistémico que se le atribuye a esta articulación modal asume un rol complementario, predominando una finalidad puramente ilustrativa. Esto también es válido para el caso particular de la imagen que, si bien tiene un lugar destacado en los libros de texto y en los planes de formación, su abordaje es limitado, dado que predomina una mirada instrumental y transparente que privilegia el campo de lo perceptivo, desatendiendo su potencial discursivo ${ }^{1}$ (Cruder, 2008).

(C) 2018 Departamento de Cs. de la Educación, Facultad de Cs. Humanas, UNRC. 
Dos textos multimodales en los cuales la imagen es protagonista son la historieta y las viñetas humorísticas. Su uso más habitual en el contexto escolar ha sido considerarlas como un recurso didáctico para desarrollar diversos contenidos curriculares desde una lógica instrumental: resolución de problemas, completamiento de actividades, etc. Como en el caso de la imagen, se desmerece la especificidad y potencial de estos géneros (Steimberg, 1997). Experiencias recientes en el campo de la historieta han abordado diversos recursos propios del género con alumnos de nivel primario (Teberosky, Portilla y Sepúlveda, 2010; Segovia Aguilar, 2012; Pantaleo, 2014; Wallner, 2017), en los cuales los niños elaboraron sus propias historietas, valiéndose de diversos recursos verbales y visuales. En cuanto al humor gráfico, su uso en el aula está orientado a la interpretación de textos y no a la producción (Schneider, 2000). En los próximos dos apartados nos abocaremos a delimitar y caracterizar este género.

\section{EL HUMOR GRÁFICO COMO TEXTO MULTIMODAL}

El humor gráfico constituye un género discursivo con características distintivas que suele articular de forma estrecha el dibujo y la escritura con fines comunicacionales y expresivos. Contrariamente a lo que $\tan$ frecuentemente se sostiene en los usos cotidianos e incluso en numerosos trabajos científicos, el humor no sólo remite a lo que es considerado como gracioso, sino que también comprende la capacidad de tomar distancia de aquello que nos produce dolor, indignación, ira para reírnos y a partir del juego, liberarnos de esos sentimientos (Freud, 1927; Pedrazzini, 2011; Steimberg, 2013). Lejos de ser sólo un divertimento, el humor gráfico permite resignificar vivencias y problematizar la realidad social. Así, a una motivación puramente lúdica del autor se suma una más ligada a la expresión de la propia identidad o comprometida con cuestiones socio-políticas (Pedrazzini y Scheuer, 2017).

Desde la ampliamente consensuada teoría de la incongruencia (Attardo, 1994; Raskin, 1985), el humor surge de la asociación de dos o más elementos incompatibles. Dicha incongruencia trae aparejada una ruptura de lo previsible; es decir, un desfase entre lo esperado y lo que en realidad ocurre. En el humor gráfico, dibujo y escritura suelen articularse de forma estrecha para producir sentido, conformando un todo: un texto en términos de Vilches (1985). En el marco de esta interacción, es posible identificar diferentes formas de relación y funcionamiento para la generación de humor: el humor se produce en el modo verbal mientras que lo visual sólo interviene de forma ilustrativa; el humor se produce en el modo visual, lo verbal puede ser incluso innecesario; el humor resulta de la interacción entre ambos modos (Tsakona, 2009), operando cada modo de forma convergente (complementaria) o divergente (contradicción parcial) (Pedrazzini y Scheuer, 2010).

El humor gráfico comparte con la historieta varias características como la estrecha articulación verbalvisual mencionada, siendo el dibujo el modo semiótico que más espacio ocupa; la escritura se inserta muchas veces en la imagen mediante globos que introducen la voz de los personajes, títulos, cartuchos, carteles y onomatopeyas. Otras características compartidas son elementos plásticos tales como las viñetas o cuadros generalmente cuadrados o rectangulares, líneas de movimiento, planos y ángulos de visión, así como formas convencionalizadas de representar gestos y emociones en los personajes e ideas abstractas a través de ideogramas (Gubern, 1972; Mc Cloud, 1994). Dentro del humor gráfico, la tira se compone de dos o más viñetas, compartiendo entonces con la historieta una secuencia narrativa que se despliega espacial y temporalmente (ver más abajo).

\section{DESAFÍOS COGNITIVOS Y SEMIÓTICOS EN EL HUMOR GRÁFICO}

La producción de humor gráfico implica a sus autores desafíos en diversos planos. A nivel procedimental, exige un dominio medianamente fluido del dibujo y la escritura como medios de representación. Estas actividades implican poner en marcha mecanismos de anticipación, revisión, comparación, evaluación en función de las propias habilidades, limitaciones, objetivos y materiales disponibles (Scheuer, de la Cruz y

(C) 2018 Departamento de Cs. de la Educación, Facultad de Cs. Humanas, UNRC. 
Pozo, 2010). La utilización de ambos modos de forma articulada para lograr una producción inteligible y humorística, evitando redundancias y contradicciones involuntarias, contribuyen también al desafío que estas actividades implican para los autores.

Otra característica del género que destacamos se refiere a los dos formatos en que se despliega el humor gráfico: la viñeta única, de un solo cuadro y la tira humorística, que implica una secuencia de dos o más cuadros. En el caso de la viñeta única, un importante desafío se encuentra en que ésta requiere condensar en una sola imagen una situación que sea comprensible y que represente el clímax de la situación humorística (Pitri, 2011) ${ }^{2}$. Otro desafío consiste en lograr una trama que sea autoconclusiva (Martignone y Prunes, 2008).

Por su parte, la tira humorística funciona dentro de una estructura narrativa que exige una construcción secuencial a partir de pocos elementos indispensables para el relato, completando diversas omisiones, lo que se ha denominado el acto de cierre o clausura (McCloud, 1994). El autor debe trabajar esta tensión a nivel narrativo para asegurar la fácil comprensión y al mismo tiempo establecer un ritmo en función de la trama: repetición o cambio de personajes, objetos y escenarios, planos, ángulos de toma, etc. (Gubern, 1972). El carácter elíptico y sintético de esta sucesión constituye un desafío también para el lector, quien debe reconstruir las secuencias de forma tal de ver el continuum de la narración (Eco, 2008). Otro tipo de tensión en la cual los autores deben trabajar de manera fina refiere a la creación del efecto humorístico, sea en el formato de viñeta única o tira, y se da entre lo que se decide mostrar (que asegura la inteligibilidad del texto) y lo que se decide no mostrar (para no arruinar el efecto sorpresa necesario en el humor).

Teniendo en mente todo lo expuesto, el objetivo principal de este trabajo es poner de relieve la potencialidad educativa de la producción de humor gráfico en niños y adolescentes. Nos proponemos mostrar que: 1) ya en esas etapas evolutivo-educativas, los niños y adolescentes son capaces de generar textos humorísticos y 2) que su realización conforma un espacio propicio para abordar temas significativos y movilizar la puesta en juego de recursos cognitivos y semióticos sofisticados.

\section{NUESTRA EXPERIENCIA: TALLERES DE PRODUCCIÓN E INTERPRETACIÓN DE HUMOR GRÁFICO}

Durante 2015 y 2016 diseñamos y dictamos seis talleres de producción e interpretación de humor gráfico en contextos educativos formales e informales en la ciudad de San Carlos de Bariloche: una escuela pública, un Centro Integrador Comunitario, un Centro de Desarrollo de la Niñez y Adolescencia, y un Encuentro de Clubes de Ciencia (organizado por el Ministerio de Ciencia y Tecnología de la Nación). En total participaron 81 niños/as y adolescentes de 9 a 18 años, quienes produjeron 121 textos humorísticos. Cinco de estos talleres consistieron en un único encuentro de dos horas de duración, mientras que el sexto se prolongó durante tres meses con total de 26 horas.

El taller de un único encuentro fue pensado en tres etapas. En una primera instancia, se realizó un intercambio en sesión plenaria basado en una presentación proyectada de alrededor de 30 minutos. Luego se destinó aproximadamente una hora a la producción individual de un texto humorístico. Al finalizar las producciones, los participantes fueron entrevistados individualmente. Esta instancia duró aproximadamente cinco minutos por participante. Todos los talleres comenzaron con un intercambio oral sobre qué es el humor y el humor gráfico, los formatos en que circula y la familiaridad de los participantes con el género. La presentación fue cuidadosamente diseñada por las investigadoras, considerando abarcar, en los diferentes formatos (viñetas únicas y tiras humorísticas), una amplia variedad de:

- autores y estilos (autores profesionales de distintos países y autores niños y adolescentes participantes de talleres previos);

- temas: desde temas lúdicos -metidas de pata ${ }^{3}$, absurdos, etc.- hasta temáticas ubicadas bajo el término humor serio (Flores, 2000) -discriminación, violencia de género, contaminación

(C) 2018 Departamento de Cs. de la Educación, Facultad de Cs. Humanas, UNRC. 
ambiental, etc.;

- recursos retóricos: hipérbole, personificación, metáfora, paradoja, alusión, ironía, metonimia, antítesis, entre otras;

- $\quad$ recursos humorísticos específicos: inversión de roles, final inesperado, ironía del destino, etc.;

- $\quad$ recursos plásticos: producciones en blanco y negro, en color, en lápiz, en tinta, con diferentes tipografías, ángulos de toma, planos, etc.;

- recursos propios del género: diversos tipos de globos, onomatopeyas, cartuchos, carteles, etiquetas, etc.

Cabe destacar que la presentación de cada recurso fue progresiva, comenzando con recursos básicos del género (personajes, escenario, globos) e incluyendo poco a poco y de acuerdo a la complejidad que reviste cada uno, diversos recursos retóricos y humorísticos.

Durante la presentación se alentó la reflexión y participación de los niños y adolescentes. Posteriormente los participantes produjeron sus propias viñetas y/o tiras humorísticas. La consigna de producción fue libre, siendo la única restricción la articulación del dibujo y la escritura. Todas las producciones fueron individuales, exceptuando una. Se ofrecieron hojas, reglas, lápices negros y de color, gomas, fibrines, fibras de color y crayones. Las encargadas del taller estuvieron dispuestas a colaborar con las inquietudes particulares. Una vez que cada participante terminó su producción, se le solicitó que contase lo que había hecho y que explicase cómo se le había ocurrido. Esto brindó información que facilitó la interpretación de producciones poco o medianamente inteligibles además de orientar sobre las motivaciones de cada niño/a y adolescente.

Por su parte, el taller de larga duración se realizó en un Centro de Desarrollo de la Niñez y Adolescencia y consistió en encuentros semanales de dos horas cada uno. En cada encuentro también se trabajó con una presentación inicial, en la cual se abordó algún contenido en profundidad: tipos de humor; formato (viñeta única y tira humorística); personajes (expresiones y gestos); escenarios; figuras retóricas; recursos humorísticos específicos; recursos plásticos; y otros recursos propios del género. La consigna de producción varió en función del contenido trabajado en cada encuentro y siempre incluyó la articulación del dibujo y la escritura. Asimismo, en algunos encuentros se propuso la producción de manera individual, y en otros, grupal.

A continuación, nos explayaremos en nuestra propuesta de considerar al humor gráfico como un objeto de enseñanza y de aprendizaje potente y atractivo. Focalizando en los 121 textos multimodales producidos por los niños/as y adolescentes y tomando tres ejemplos como base, daremos cuenta de los temas abordados, los formatos elegidos y diversos recursos verbales, visuales y multimodales puestos en juego. Concluiremos este trabajo con algunas ideas centrales y discutiremos ciertas implicancias educativas.

\section{EL HUMOR GRÁFICO COMO UN OBJETO DE APRENDIZAJE EN Sí MISMO}

\section{Los temas y las motivaciones del autor}

El humor gráfico no tiene límite de temas, aborda problemáticas de actualidad, situaciones endémicas, costumbres sociales. Los temas están ligados a las motivaciones de los autores que, como hemos señalado, pueden ser lúdicas, comprometidas o remitir a la identidad del autor. El humor gráfico deviene así un medio para comunicar y expresar una visión personal sobre una situación determinada.

En los talleres no hubo consignas temáticas, sino que los tópicos tratados por niños/as y adolescentes fueron elegidos por ellos mismos. En el taller de larga duración, un encuentro versó sobre el humor serio, en el que se abordaron diversas problemáticas de actualidad, tales como la pobreza, discriminación

(C) 2018 Departamento de Cs. de la Educación, Facultad de Cs. Humanas, UNRC. 
racial, contaminación, hambre, violencia de género, entre otros, pero más allá de este marco general, fueron ellos quienes debieron elegir qué tópico trabajar.

Del total de 121 textos producidos, el 55\% refirió a situaciones fantasiosas, con personajes imaginarios creados por los participantes o, en el menor de los casos, mediáticos, mientras que el $45 \%$ versó sobre situaciones realistas. Los tópicos remitieron a burlas, metidas de pata, aventuras, juegos (25\%), sentimientos, desamores, reflexiones existenciales (25\%), prácticas cotidianas y creencias culturales (28\%) y conflictos sociales (20\%). Un escaso número de producciones $(2 \%)$ consistió en dibujos de paisajes u objetos, no ateniéndose a la consigna de producir un texto humorístico.

En cuanto a las motivaciones de los autores, el $68 \%$ fue de tipo lúdico, siendo el motivo principal divertir al lector; el $21 \%$ fue de naturaleza comprometida, en tanto los autores presentaron una reflexión y/o una denuncia; y $11 \%$ combinó lo lúdico con lo comprometido.

Seleccionamos para este trabajo tres textos humorísticos para ilustrar los diferentes apartados. Las Figuras 1 y 2 son producciones individuales y la Figura 3 una producción grupal. La Figura 1 se realizó en el taller de humor gráfico de único encuentro brindado durante un Encuentro de Clubes de Ciencia en San Carlos de Bariloche. La Figura 2 se realizó hacia el final del taller de larga duración, por lo cual ya se había recorrido un camino de exploración de diferentes formatos, temas, recursos plásticos, humorísticos, retóricos, etc. La Figura 3 se realizó hacia la mitad del taller de larga duración, bajo la consigna de producción de un texto humorístico que verse sobre humor serio.

La Figura 1 remite a una práctica habitual, la vacunación, pero desde una mirada humorística en la que predomina una motivación lúdica. La Figura 2 refiere a una problemática recurrente en nuestra sociedad, la contaminación ambiental. En este caso la autora evoca cómo afecta en la fauna marina el derrame de petróleo, asumiendo una motivación de compromiso.

Figura 1. Yamila, 17 años

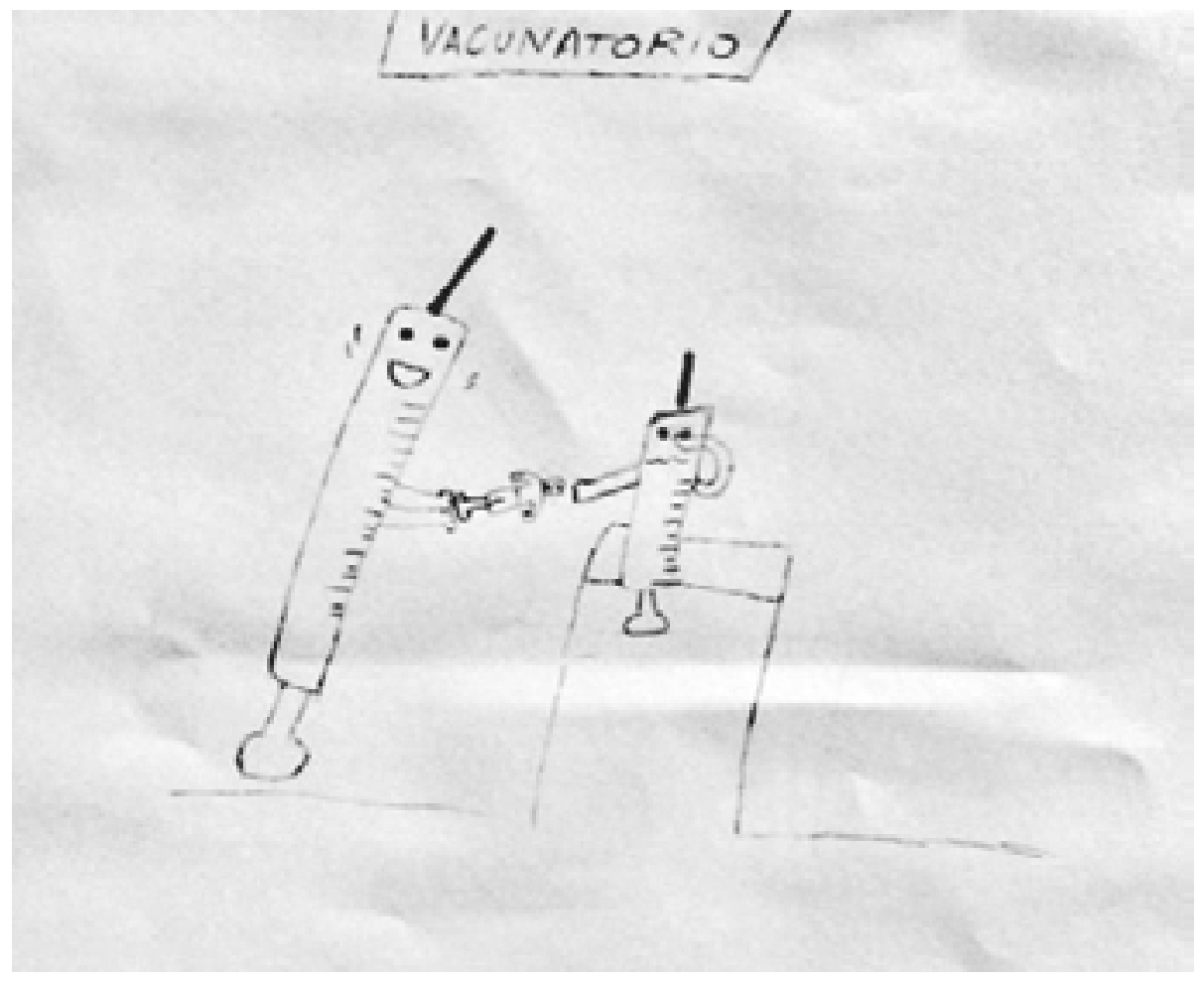


Figura 2. María, 13 años.

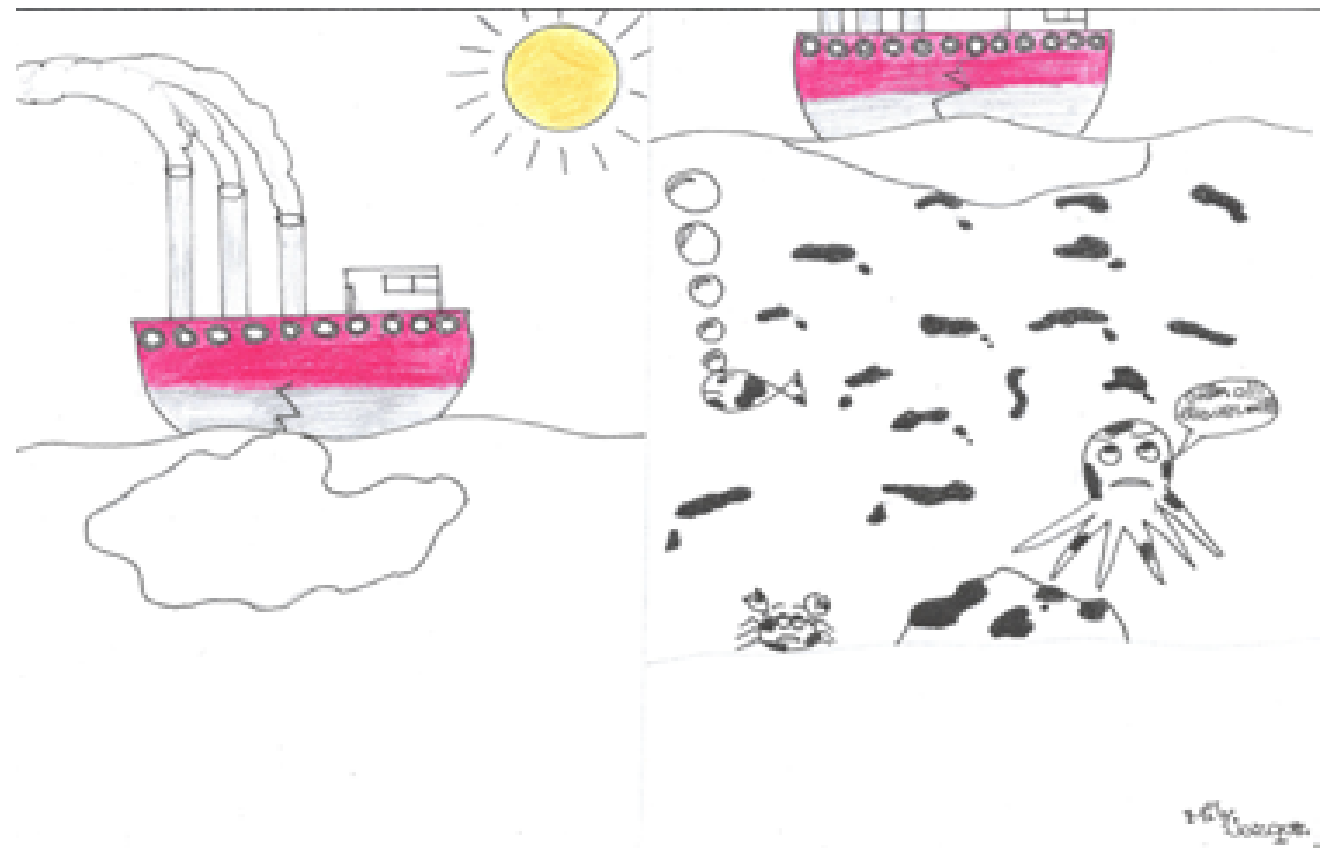

Globo: iOhh, no!!! iOtra vez no!!!

En la Figura 3, las autoras abordan una problemática de actualidad, la violencia de género, denunciando la existencia de un doble discurso en una fracción de la sociedad; en público muestra una faceta socialmente aceptada que no se corresponde con la forma en que se comporta en un círculo privado. La motivación de las autoras da cuenta así de un fuerte compromiso.

Figura 3. María y Josefina, 13 y 11 años respectivamente.

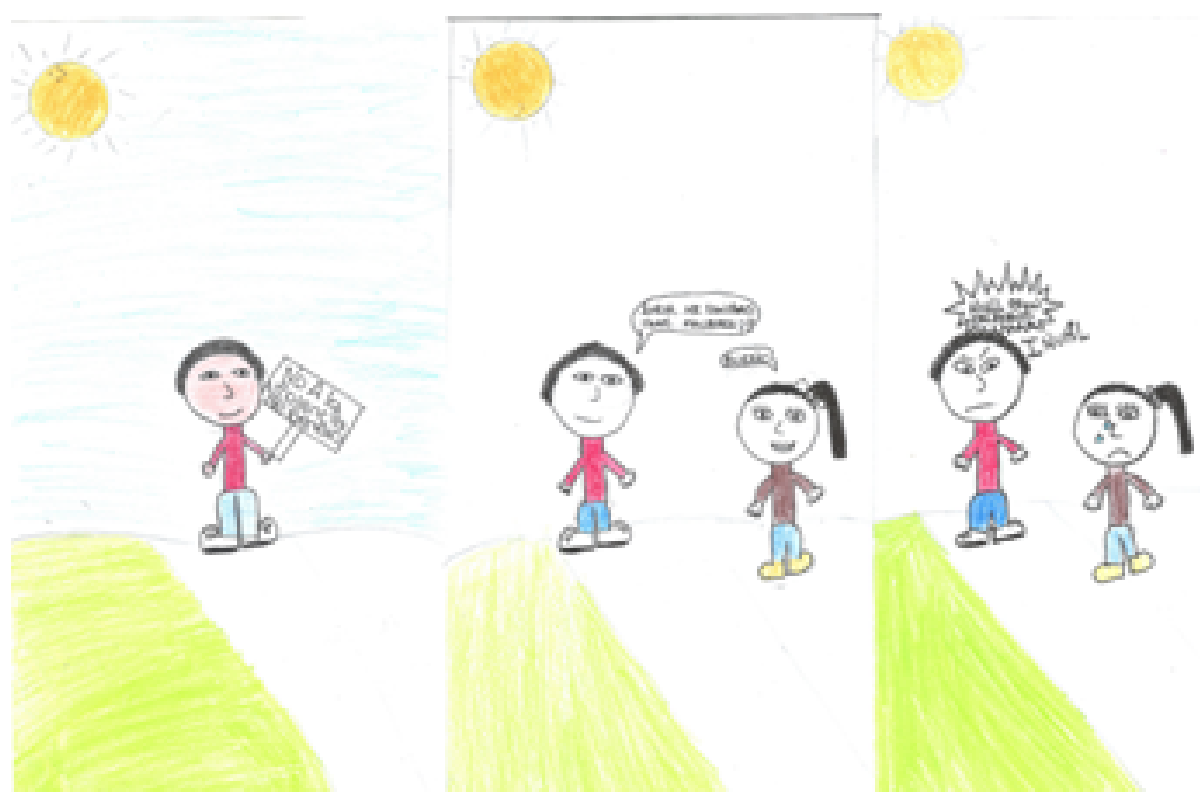

Viñeta 1: Cartel: No a la violencia de género

Viñeta 2: Globo 1: ¿Amor, me comprás unos Malboros? / Globo 2: Bueno

Viñeta 3: Globo de grito: Eran Malboros. INUTIL.

(C) 2018 Departamento de Cs. de la Educación, Facultad de Cs. Humanas, UNRC. 


\section{Viñeta única versus tira}

Elegir en qué formato desplegar la producción no es una decisión menor, ya que como hemos visto, la viñeta única y la tira presentan importantes diferencias discursivas, cada una con desafíos cognitivos y semióticos particulares. Los participantes de los talleres no tuvieron restricciones respecto a qué formato utilizar en sus producciones, exceptuando dos encuentros del taller de larga duración, uno sobre tiras y otro sobre viñeta única. Del total de 121 textos humorísticos producidos, 61 fueron viñetas únicas y 60 tiras. Vemos así que el recurso a uno u otro formato fue muy parejo.

La Figura 1, de una única viñeta, representa eficazmente el clímax de la situación humorística captando el momento en que dos jeringas se pasan a un humano para vacunarlo. La Figura 2 comprende dos viñetas. La primera muestra, a partir de un plano general, un barco en el mar que está derramando petróleo por una fractura en su base. En la segunda viñeta, el cambio de ángulo de toma, en contrapicado, permite ver lo que ocurre en el fondo del mar por el petróleo derramado, manteniendo el lazo causal con el barco, que es ubicado en la parte superior de la viñeta. En la Figura 3, la sucesión de textos verbales (cartel y globos), un segundo personaje que aparece y el contraste de expresiones faciales marcan el ritmo de la tira. Simultáneamente, hay un gran cuidado puesto en la repetición de personajes, reconocibles fácilmente por su fisonomía y vestimenta, así como del escenario, que es exactamente el mismo, aunque sólo en la primera viñeta el personaje y el cielo hayan sido coloreados en su totalidad. Contrariamente a lo que ocurre en la Figura 2, no se confiere ritmo a la narrativa a partir de cambios de planos ni de ángulos de toma, sino que se mantiene un plano general y un ángulo de toma normal.

\section{Recursos verbales, visuales y multimodales desplegados}

En los textos humorísticos producidos, los niños/as y adolescentes pusieron en juego una gran diversidad de recursos. A nivel verbal, usaron títulos ("Vacunatorio", "La historia de por qué las ranas no tienen pelo", etc.); cartuchos que situaban espacial y temporalmente la escena (por ej.: "Dos días después", "En un callejón"); carteles insertados en escenarios públicos con funciones variadas como indicar una toma de posición ("No al maltrato animal", "No a la violencia de género") o advertir algo ("Cuidado, pozo grande"); globos de habla, grito y pensamiento; onomatopeyas ("BOM!", "Pío, pío", "Boing"). A nivel visual, representaron personajes humanos, animales o artefactos personificados (es decir, con características humanas), a los cuales atribuyeron emociones y acciones reconocibles y los situaron en diversidad de escenarios. Se valieron de numerosas figuras retóricas verbales y visuales como juegos de palabras (presentes a nivel exclusivamente verbal), metáforas, metonimias, antítesis, ironías, alusiones, paradojas; referencias a un bagaje cultural compartido, como letras de canciones, personajes de cuentos, creencias y tradiciones (por ej.: qué hacer para sacar el hipo, la inauguración de un barco); y recursos más específicamente humorísticos como la inversión de roles y el absurdo.

En muchos textos lograron articular estrechamente el dibujo y la escritura para la producción de sentido. En cuanto a la producción de humor, identificamos todas las funciones descritas anteriormente: textos en los que el disparador (trigger, Raskin, 1985) humorístico es mayormente verbal (Figura 3), otros en los que es visual (Figura 1), otros en los que el disparador opera a partir de una convergencia (Figura 2) o de una contradicción parcial de modos.

En la Figura 1, el título refuerza el lugar donde transcurre la escena representada visualmente. La autora utiliza un recurso humorístico muy habitual en el género del humor (Bergson, 2008), que encontró bastante eco en los textos producidos por los participantes de los talleres realizados: la inversión de roles. Así, no es un humano quien manipula una jeringa sino al revés, inversión que se efectúa por la acción de las jeringas personificadas y por el gran tamaño de éstas contrastado con el pequeño tamaño del hombre que se transforma en vacuna. Asimismo, la diferencia de tamaño y la antítesis de emociones entre las dos jeringas (una grande sonríe mientras la otra, más pequeña, está inquieta y atemorizada) puede remitir a la relación enfermero-paciente/niño. En la Figura 2, la autora acude a la personificación 
de animales, dotándolos de estados emocionales de inquietud y tristeza, que se advierten por las expresiones faciales (cejas y boca) así como por la frase atribuida al pulpo. Es interesante cómo logra construir la idea de recurrencia de la situación representada de forma sintética e indirecta, a partir de una complementariedad verbal-visual. La exclamación del pulpo sólo puede ser entendida en relación con la imagen de los animales empetrolados, y a su vez con la grieta en el barco, conformando esta relación causal una metonimia.

En la Figura 3, el uso de un cartel o de globos marca el ámbito al que corresponde la situación, público en el primer caso y privado en el segundo. El globo de grito, con puntas zigzagueantes en la tercera viñeta, y la tipografía de la palabra "inútil" en mayúscula y resaltada, construye eficazmente el clima emocional de la situación, que se articula con las expresiones de enojo (a través de cejas, ojos y boca) y tristeza (boca y lágrima) de los personajes. Estas expresiones faciales contrastan (antítesis) con las de las dos primeras viñetas, en las que los personajes sonríen y se los ve plácidos. La denuncia de una actitud hipócrita es operativizada a través de una paradoja, figura retórica que establece relaciones lógicas que van en contra de la lógica común (Fromilhague, 2005).

\section{CONCLUSIONES E IMPLICANCIAS EDUCATIVAS}

En el marco de las nuevas demandas en torno a la alfabetización integral que implica el actual contexto educativo, en este trabajo aducimos que el humor gráfico es un género discursivo potente para ser introducido en el aula, no sólo a la hora de abordar diversos temas de actualidad social y política desde la mirada de quienes son profesionales del humor gráfico, como es el enfoque habitual, sino también incentivando la producción de los propios alumnos ${ }^{4}$. Lejos de cumplir una función meramente de entretenimiento, la versatilidad de este género permite abordar una amplísima variedad temática, haciendo posible resignificar experiencias vividas, denunciar una situación que indigna, mantener vivo, transformar y compartir un patrimonio cultural. Esto posibilita además un trabajo profundo sobre las múltiples perspectivas que las personas pueden desarrollar sobre una misma temática.

Tanto el intercambio en sesión plenaria como los textos humorísticos producidos por los niños y adolescentes participantes de los talleres de humor gráfico evidencian que ellos no sólo se implicaron en la producción de las viñetas, disfrutando de la actividad, sino que además usaron la ocasión para abordar temas significativos y en algunos casos incluso conflictivos, se plantearon complejos desafíos cognitivos y semióticos al poner en juego diversos recursos verbales, visuales y multimodales y algunos de ellos alcanzaron soluciones originales y/o sofisticadas.

Consideramos que estos primeros resultados presentados ponen de relieve el interés de proponer el humor gráfico como objeto de enseñanza y de aprendizaje en contexto escolar, tanto en nivel primario como medio, ya sea con intervenciones puntuales en torno a determinadas temáticas y/o recursos gráficos o bien con una planificación de mediano o largo plazo (ver los trabajos de Teberosky, Portilla y Sepúlveda, 2010; Segovia Aguilar, 2012; Pantaleo, 2014; Wallner, 2017). En este sentido, en el marco de nuestra investigación, planeamos dictar talleres de capacitación docente, así como también elaborar un manual con el doble objetivo de brindar una justificación teórica interdisciplinaria sobre el humor gráfico como objeto de enseñanza y de aprendizaje y propuestas didácticas para su trabajo en el aula.

El corpus de textos humorísticos obtenido hasta la fecha nos permitirá, en próximos trabajos, realizar un análisis evolutivo en cuanto a las habilidades semióticas y cognitivas desplegadas por niñas, niños y adolescentes para ideary representar situaciones humorísticas; las temáticas elegidas en sus producciones; las motivaciones que orientan su producción y los recursos visuales, verbales y multimodales puestos en juego. Otros trabajos ulteriores también estarán enfocados a estudiar la trayectoria de los participantes del taller de larga duración en relación con los textos humorísticos producidos. 


\section{NOTAS}

1. Una excepción sería Educación Artística, en la que sí se abordan características formales de la imagen en tanto modo semiótico (Cruder, 2008).

2. En su estudio con niños de 4,5 a 12 años, Pitri (2011) ha observado la dificultad que tienen los niños menores de 7 años para representar gráficamente aquello que les resulta gracioso, completando la narración oralmente.

3. Expresión coloquial que significada cometer un fallo, equivocarse.

4. Numerosos docentes participantes de nuestros talleres se han referido a la riqueza y el atractivo del humor gráfico como disparador para abordar contenidos sociales y políticos. A modo de ejemplo, un docente de Historia de nivel medio se entusiasmó con la idea de trabajar con sus alumnos un período histórico particular a partir del humor gráfico que circulaba en la época y proponerles luego crear sus propias viñetas en torno a dicho tema.

\section{Agradecimientos}

Agradecemos muy especialmente a nuestra querida compañera y amiga Mónica Echenique, con quien dimos los primeros pasos en la construcción de este vínculo entre humor gráfico y educación.

\section{REFERENCIAS}

Attardo, S. (1994). Linguistic theories of humor. Berlín, Alemania: Walter de Gruyter \& Co.

Bergson, H. (2008). [1900]. La risa. Ensayo sobre la significación de lo cómico. Madrid, España: Alianza.

Cruder, G. (2008). La educación de la mirada. Sobre los sentidos de la imagen en los libros de texto. Buenos Aires, Argentina: La Crujía.

Eco, U. (2008) [1964]. Apocalípticos e integrados. Buenos Aires, Argentina: Tusquets editores.

Flores, A. B. (2000). Humor y posmodernidad: el humor serio. En AAVV La Argentina humorística. Cultura y discurso en los noventa. Córdoba, Argentina: Ferreyra editor.

Freud, S. (1992) [1927]. El Humor. En Obras completas. Buenos Aires, Argentina: Amorrortu editores, Vol. XXI.

Fromilhague, C. (2005). Les figures de style. París, Francia: Nathan.

Gubern, R. (1972). El lenguaje de los comics. Barcelona, España: Península.

Jewitt, C. (2009). (Ed). The Routledge Hanbook of Multimedial Analysis. Londres, Inglaterra: Routledge.

Kress, G. (2010). Multimodality: A social semiotic approach to contemporary communication. Londres, Inglaterra: Routledge.

Martignone, H. y Prunes, M. (2008). Historietas a diario. Las tiras cómicas argentinas de Mafalda a nuestros días. Buenos Aires, Argentina: Libraria.

McCloud, S. (1994). Understanding comics. The Invisible Art. New York, USA: Harper Perennial.

Pantaleo, S. (2014). Language, Literacy and Visual Texts. English in Education 0(0), 1-17.

Pedrazzini, A. (2011). La construction de l'image présidentielle dans la presse satirique: vers une grammaire de l'humour. Jacques Chirac dans l'hebdomadaire français Le Canard enchaîné et Carlos Menem dans le supplément argentin Sátira/12. Portal e-sorbonne. Universidad Paris-Sorbonne. Recuperado de: www.theses.fr/2010PA040203.pdf 
Pedrazzini, A. y Scheuer, N. (2017). La geografía del humor gráfico actual: tensiones entre lo local y lo trans-cultural. En Flores, A. B. (coord.). El rumor del humor: Jornadas de Investigación: innovación, rupturas y transformaciones en la cultura humoristica argentina. Córdoba, Argentina: Universidad Nacional de Córdoba. Recuperado de: http://www.ffyh.unc.edu.ar/sites/default/files/e-books/ EBOOK HUMOR.pdf

Pedrazzini, A. y Scheuer, N. (2010). La interacción lingüística e ícono-plástica en la producción de caricaturas políticas: un estudio funcional y retórico. IRICE Nueva época, 21, 95-111.

Pitri, E. (2011).Children's funny art and the form it can take over time. International Journal of Education through Art 7(1), 81-96.

Raskin, V. (1985). Semantic mechanisms of humor. Dordrecht, Países Bajos: D. Reidel Publishing Company.

Scheuer, N.; de la Cruz, M. y Pozo, J.I. (2010). Aprender a dibujar y a escribir. Las perspectivas de los niños, sus familias y maestros. Buenos Aires, Argentina: Noveduc.

Segovia Aguilar, B. (2012). La adquisición de la competencia narrativa a través del cómic en la Escuela Primaria. Revista Complutense de Educación, 23(2), 375-399.

Schneider, J-B. (2000). Lecture d'images. Clès pour le dessin d'humour - Lire, analyser, produire avec les enfants de 9 à 15 ans. Schiltigheim, Francia: Editions Accès.

Steimberg, O. (2013). Leyendo historietas. Textos sobre relatos visuales y humor gráfico. Buenos Aires, Argentina: Eterna Cadencia Editora.

Steimberg, O. (1997). La historieta en la escuela: el descubrimiento del estilo. En Steimberg, O. y Traversa, O. Estilo de época y comunicación mediática. Buenos Aires, Argentina: Atuel.

Teberosky, A.; Portilla, C. y Sepúlveda, A. (2010). Las convenciones del comic para representar el discurso narrativo. Una experiencia en segundo primaria. Revista IRICE, 21, 45-63.

Tsakona, V. (2009). Language and image interaction in cartoons: Towards a multimodal theory of humor. Journal of Pragmatics, 41, 1171-1188.

Vilches, L. (1984). La lectura de la imagen. Prensa, cine, televisión. Buenos Aires, Argentina: Paidós.

Wallner, L. (2017). Speak of the Bubble - Constructing Comic Book Bubbles as Literary Devices in a Primary School Classroom. Journal of Graphic Novels and Comics, 8(2), 173-192.

Artículo recibido: 16 de agosto de 2017

Artículo aceptado: 21 de marzo de 2018 